\title{
Assessment of Migraine Disability Using the Migraine Disability Assessment Questionnaire in Young Nigerians
}

\author{
Birinus Adikaibe Ezeala-Adikaibe ${ }^{1,2^{*}}$, Chinwe Onyekonwu1 ${ }^{1}$, Uchenna Ijoma1, Nkeiru Mbadiwe ${ }^{1}$, \\ Oluchi Stella Ekenze', Casmir Orjioke ${ }^{2}$, Ekenechukwu Young1, Peter Chime' ${ }^{2}$, Obinna Onodugo ${ }^{1}$, \\ Obumneme Anyim², Chidimma Brenda Nwatu1, Celestine Okwara1, \\ Ikenna Obinwanne Onwuekwe ${ }^{1}$
}

\author{
${ }^{1}$ Department of Medicine, University of Nigeria Teaching Hospital, Enugu, Nigeria \\ ${ }^{2}$ Department of Medicine, Enugu State University of Science and Technology, Enugu, Nigeria \\ Email: *birinusadikaibe@gmail.com
}

How to cite this paper: Ezeala-Adikaibe, B.A., Onyekonwu, C., Ijoma, U., Mbadiwe, N., Ekenze, O.S., Orjioke, C., Young, E., Chime, P., Onodugo, O., Anyim, O., Nwatu, C.B., Okwara, C. and Onwuekwe, I.O. (2018) Assessment of Migraine Disability Using the Migraine Disability Assessment Questionnaire in Young Nigerians. World Journal of Neuroscience, 8, 411-422. https://doi.org/10.4236/wjins.2018.84032

Received: September 10, 2018

Accepted: October 15, 2018

Published: October 18, 2018

Copyright $\odot 2018$ by authors and Scientific Research Publishing Inc. This work is licensed under the Creative Commons Attribution International License (CC BY 4.0).

http://creativecommons.org/licenses/by/4.0/

\begin{abstract}
Background and purpose: Migraine is a common debilitating condition with variable prevalence in young Nigerians with significant deterioration in normal daily functioning and in the quality of life. Few data exist on the disability of migraine in Nigeria. The aim of this study was to measure the headache related disability of patients with migraine using the MIDAS among young Nigerians. Methods: This was a cross sectional study conducted in Enugu South East Nigeria. The questionnaire was designed to assess headache profiles according to ICHD-III beta and disability using the Migraine Disability Assessment Questionnaire. Results: About $40.6 \%$ of migraineurs were concerned about headache attacks and $39.1 \%$ consulted a doctor because of migraine. Most students were affected due to reduced effectiveness at school and number of days missed from housework- $18.8 \%$ and $20.3 \%$ respectively. Overall, $47.8 \%$ had at least one day affected by headache in the last three months. The mean number of days disabled by headache was 14.3 days. The mean headache frequency was 5.7 days and the mean pain intensity was 4.2. About $27.5 \%$ of the migraineurs had moderate to severe disability due to migraine. There were no significant differences between males and females. Conclusion: Most with migraine experienced reduction in effectiveness at school and number of days missed from housework. Overall, $47.8 \%$ had at least one day affected by headache with an average of 14.3 days disabled by headache and $27.5 \%$ of the migraineurs had moderate to severe disability due to migraine.
\end{abstract}

\section{Keywords}

Migraine, Disability, Students, Nigerians 


\section{Introduction}

Migraine is a common debilitating condition with variable prevalence in Nigeria [1]-[7]. People with migraine experience substantial headache impact on daily activities, increased direct and indirect medical costs, health care resource utilization, reduced health-related quality of life and higher rates of comorbidities [8] [9] [10]. It is a growing public health problem with an estimated $5.61 \%$ prevalence and affecting nearly 56 million people in Africa especially the young [11] [12] [13]. As a chronic disorder, migraine causes significant deterioration in normal daily functioning and in the quality of life [8] [9] [10] [11] [12] [14] [15] [16]. In a continent where diseases are still attributed to spiritual causes, and local healing methods are widely practiced, the burden of migraine is likely to be enormous. Few data exist on the disability of migraine in Nigeria [3] [6] [7].

A common way of measuring the burden of migraine is by characterizing the disability associated with it using the Migraine Disability Assessment (MIDAS) Questionnaire [16] [17]. The MIDAS questionnaire has proven itself as an efficient tool in clinical practice, but it is more likely to capture very severe forms of headache [17] and therefore may underestimate the true impact of migraine in the community. The aim of this study was to measure the headache related disability of patients with migraine using the MIDAS among young Nigerians.

\section{Methods}

This was a cross sectional study conducted in Enugu South East Nigeria. Participants were drawn from two secondary schools and two tertiary institutions in Enugu urban and were evaluated in their respective schools. This study was part of a health awareness campaign in June 2015. Study duration was 2 weeks. The questionnaire was designed to assess demographic data and headache profiles according to ICHD-III beta [18]. Questionnaires were self-administered and retrieved the same day. Data obtained were manually sorted and coded into a personal computer. The study protocol was reviewed and approved by the ethics committee of the University of Nigeria Teaching Hospital Enugu.

Using the formula: [19] $\mathrm{N}=\mathrm{D} \times \mathrm{Z}^{2} \times \mathrm{P}(1-\mathrm{P}) / \mathrm{d}^{2}$. Where $\mathrm{N}=$ desired sample size. $\mathrm{P}=$ prevalence rate of migraine $6.4 \%, \mathrm{D}=$ design effect $=2$, and $\mathrm{d}=$ desired precision limit assumed at $5 \% . \mathrm{N}=2 \times(1.96)^{2} \times 0.064 \times 0.936 / 0.0025=2 \times$ $3.8416 \times 0.040704 / 0.0025=125$. Assuming $10 \%$ attrition, a sample size of 137 and above was used.

All participants gave their informed consent. Ethical clearance was obtained from the Ethics committee of the University of Nigeria Teaching Hospital Enugu.

The lifetime prevalence of migraine was defined according to ICHD-III beta [19]. The MIDAS ${ }^{17}$ questionnaire consists of 7 questions referring to the impact of migraine in 3 activity domains: work/school, housework, social and leisure activities-all these are evaluated for the preceding 3 months. The MIDAS score is derived as the sum of responses to questions 1 through 5. Two additional 
questions assessing frequency and intensity of pain on the MIDAS questionnaire were not included in the MIDAS score. The 4-point grading system for the MIDAS questionnaire is as follows: grade I (scores ranging from 0 to 5), little or no disability, grade II (scores ranging from 6 to 10), mild disability, grade III (scores ranging from 11 to 20 ), moderate disability, grade IV (21 or greater) severe disability.

For database management and statistical analyses, we used GraphPad Prism version 6, (GraphPad Software, La Jolla California USA). Descriptive statistics were used to analyze the demographic data. The differences in the mean scores in MIDAS questions were tested statistically using the nonparametric Mann-Whitney test. Proportions were compared using the Chi squared test or Fishers exact test. Age was compared using the student's T test. We considered $\mathrm{P}$ $<0.05$ as statistically significant.

\section{Results}

\subsection{Headache Subtypes}

A total of 759 (aged 15 - 36 years) individuals were interviewed. Males were 308 (40.6\%) and females $451(59.4 \%) \mathrm{P}<0.001$. The male to female ratio was 1:1.5. The mean age of the participants was 21.6 years (95\% CI 21.6 - 21.9). Males (mean age 22.7, 95\% CI 22.3 - 23.1) were older than females (mean age, 20.9, $95 \%$ CI $20.5-21.2) \mathrm{P}<0.001$. The majority of the students were aged between 20 - 25 years of age (51.5\%) and were in tertiary institutions (Table 1).

\subsection{Migraine}

A total of 69 (9.1\%, 95\% CI 7 - 11.1) had migraine. The prevalence of migraine and its subtypes are shown in Table 2. It was similar in females 10\% (95\% CI 7.2 - 12.7) and males 7.8\%, (95\% CI 4.8 - 10.9), $\mathrm{P}=0.304$. Migraine with aura, $1.6 \%$, (95\% CI 0.7 - 2.3) and migraine without aura 6.5\%, (95\% CI $0.5-8.2)$ were also similar in both males and females. The prevalence of migraine was lowest after 24 years. The prevalence of migraine was also similar in secondary and university students.

Table 1. Age, sex and level of education of the total population.

\begin{tabular}{cccc}
\hline & Males & Female & Total \\
& $\mathrm{N}(\%)$ & $\mathrm{N}(\%)$ & $\mathrm{N}(\%)$ \\
\hline Age Groups (years) & - & - & - \\
$<20$ & $52(16.9)$ & $140(31)$ & $192(25.4)$ \\
$20-25$ & $151(49)$ & $240(53.2)$ & $391(51.5)$ \\
$\geq 25$ & $105(34.4)$ & $71(15.7)$ & $176(23.2)$ \\
- & - & - & - \\
Level of Education & - & - & - \\
Secondary & $22(21.4)$ & $81(78.6)$ & $103(13.6)$ \\
Tertiary & $286(43.6)$ & $370(56.4)$ & $656(86.4)$ \\
- & - & - & - \\
Total & $308(40.7)$ & $451(59.3)$ & $759(100)$ \\
\hline
\end{tabular}


Table 2. Distribution of Migraine.

\begin{tabular}{ccccc}
\hline & Males & Females & Total & P value \\
\hline MIGRAINE & $24(4.8-10.8)$ & $45(10,7.2-12.7)$ & $69(9.1,7-11.1)$ & 0.304 \\
Age Group & - & - & - & - \\
$<20$ & $8(15.4,5.6-25.2)$ & $11(7.9,3.4-12.3)$ & $19(9.9,5.7-14.1)$ & - \\
$20-24$ & $12(7.9,3.6-12.3)$ & $24(10,6.2-13.8)$ & $36(9.2,6.3-12.1)$ & - \\
$\geq 25$ & $4(1.9,0.1-7.5)$ & $10(14.1,6-22.2)$ & $14(7.9,3.9-11.8)$ & 0.721 \\
Level of Education & - & - & - & - \\
Secondary & $2(9.1,-2.9-21.1)$ & $6(7.4,1.7-13.1)$ & $8(7.8,2.5-12.9)$ & - \\
Tertiary & $22(7.8,4.6-10.8)$ & $39(10.5,7.4-13.7)$ & $61(9.3,7.1-11.5)$ & 0.704 \\
MIGRAINE WITH AURA & $4(1.3,0-2.5)$ & $8(1.8,0.6-3)$ & $12(1.6,0.7-2.5)$ & - \\
MIGRAINE WITHOUT & $20(6.5,3.7-9.2)$ & $37(8.1,6-10.7)$ & $49(6.5,4.7-8.2)$ & 0.908 \\
AURA & & & & \\
\hline
\end{tabular}

Table 3 shows that $40.6 \%$ of migraineurs were concerned about headache attacks and $39.1 \%$ consulted a doctor because of migraine. Similar proportions (30.4\%) used medications for headache and said the headache affected their overall performance at school in the last three months. About a quarter reported a family history of primary headache.

The proportion of the people with migraine who were affected by the different criteria of the MIDAS questionnaire is shown in Table 4. There were no significant differences between the proportions of males and females who were affected by migraine in at least five days in the preceding 3 months. In MIDAS question $1,2.9 \%$ of migraineurs missed school at least 5 days. Most students were affected due to reduced effectiveness at school and number of days missed from housework- $18.8 \%$ and $20.3 \%$ respectively. Overall, $47.8 \%$ had at least one day affected by headache in the last three months.

Table 5 displays the mean MIDAS scores and Table 6 the levels of disability of migraineurs and their sex distribution. The overall mean number of days during which sufferers were disabled by headache was 14.3 days. The score ranged from 1.6 days missed from school to 4.7 days missed from housework. There were no statistical significant differences between the proportion of males and females who were affected.

The mean number of headache days was 5.7 days and the mean pain intensity was 4.2. Distribution of disability scores shows that $27.5 \%$ of the migraineurs had moderate to severe disability due to migraine. There were also no significant differences between males and females (Table 7).

\section{Discussion}

The migraine is a common chronic condition among young Nigerians Africans [1]-[7] however, little is known about it on this group in the continent. The lifetime prevalence of migraine in this study was $9.1 \%$ similar in males and females. The burden of migraine measured using the MIDAS criteria, headache frequency and intensity were also similar in both sexes. The mean number of days affected by headache was 14.3 days including 1.6 days missed of school to 4.7 days 
Table 3. Factors affecting students with migraine.

\begin{tabular}{ccccc}
\hline & Males & Females & Total & P value \\
\hline $\begin{array}{c}\text { Concerned about headaches } \\
\text { Yes }\end{array}$ & - & - & - & - \\
$\begin{array}{c}\text { I have used medications within the } \\
\text { last } 3 \text { months } \\
\text { Yes }\end{array}$ & - & $19(42.2)$ & $28(40.6)$ & 0.704 \\
$\begin{array}{c}\text { Visited a doctor for treatment } \\
\text { Yes }\end{array}$ & $-(33.3)$ & $13(28.9)$ & $21(30.4)$ & 0.702 \\
$\begin{array}{c}\text { School Performance } \\
\text { Rarely }\end{array}$ & - & - & - & - \\
Often & $12(50)$ & $15(33.3)$ & $27(39.1)$ & 0.177 \\
Family history & - & - & - & - \\
Yes & $16(66.7)$ & $32(71.1)$ & $48(69.6)$ & - \\
Total & $8(33.3)$ & $13(28.9)$ & $21(30.4)$ & 0.702 \\
$\quad$ & - & - & - & - \\
& $7(29.2)$ & $10(22.2)$ & $17(24.6)$ & 0.407 \\
& $24(7.8)$ & $45(10)$ & $69(9.1)$ & 0.087 \\
\hline
\end{tabular}

Table 4. MIDAS Scores: Proportion of individuals affected by migraine in the preceding 3 months.

\begin{tabular}{|c|c|c|c|c|}
\hline Questions & Males & Females & Total & $P$ value \\
\hline Question 1: & - & - & - & - \\
\hline Days missed from school & - & - & - & - \\
\hline $0-4$ & $24(100)$ & $43(95.6)$ & $67(97.1)$ & - \\
\hline$\geq 5$ & - & $2(4.4)$ & $2(2.9)$ & 0.540 \\
\hline Question 2: & - & - & - & - \\
\hline Reduce effectiveness days at school & - & - & - & - \\
\hline $0-4$ & $21(87.5)$ & $35(77.8)$ & $56(81.2)$ & - \\
\hline$\geq 5$ & $3(12.5)$ & $10(22.2)$ & $13(18.8)$ & 0.519 \\
\hline Question 3: & - & - & - & - \\
\hline Days missed from housework & - & - & - & - \\
\hline $0-4$ & $19(79.2)$ & $36(80)$ & $55(79.7)$ & - \\
\hline$\geq 5$ & $5(20.8)$ & $9(20)$ & $14(20.3)$ & 0.935 \\
\hline Question 4: & - & - & - & - \\
\hline Reduced effectiveness in housework & - & - & - & - \\
\hline $0-4$ & $21(87.5)$ & $41(91.1)$ & $62(89.9)$ & - \\
\hline$\geq 5$ & $3(12.5)$ & $4(8.9)$ & $7(10.1)$ & 0.687 \\
\hline Question 5: & - & - & - & - \\
\hline Days missed from family, social or leisure & - & - & - & - \\
\hline activities & - & - & - & - \\
\hline $1-4$ & $22(91.7)$ & $42(93.3)$ & $64(92.8)$ & - \\
\hline$\geq 5$ & $2(8.3)$ & $3(6.7)$ & $5(7.2)$ & 1 \\
\hline Total number of days affected & - & - & - & - \\
\hline 0 & $14(58.3)$ & $22(48.9)$ & $36(52.2)$ & - \\
\hline $1-5$ & $1(4.2)$ & $6(13.3)$ & $7(10.1)$ & - \\
\hline $6-10$ & $3(12.5)$ & $4(8.9)$ & $7(10.1)$ & - \\
\hline $11-20$ & $3(12.5)$ & $7(15.8)$ & $10(14.5)$ & - \\
\hline$\geq 21$ & $3(12.5)$ & $6(13.3)$ & $9(13)$ & 0.759 \\
\hline
\end{tabular}

missed of housework. The mean number of headache days was 5.7 days and the mean pain intensity was 4.2 days in the preceding three months. About $27.5 \%$ of 
Table 5. MIDAS Score: Mean and range of scores in the preceding 3 months.

\begin{tabular}{|c|c|c|c|c|c|}
\hline Questions & Males & Females & Ratio & Total & P-value \\
\hline Question 1: Days missed & - & - & - & - & - \\
\hline from school & - & - & - & - & - \\
\hline Mean $(95 \% \mathrm{CI})$ & $0.6(-0.1-1.2)$ & $2.2(-5-4.9)$ & $0.3: 1$ & $1.6(-0.1-3.4)$ & 0.395 \\
\hline Range & $0-5$ & $0-60$ & - & $0-60$ & - \\
\hline Question 2: Reduction in & - & - & - & - & - \\
\hline effectiveness days at & - & - & - & - & - \\
\hline school & - & - & - & - & - \\
\hline Mean $(95 \%$ CI $)$ & $1.6(0.2-3)$ & $4.8(0.6-9)$ & $0.3: 1$ & $3.7(0.9-6.4)$ & 0.274 \\
\hline Range & $0-10$ & $0-90$ & - & $0-90$ & - \\
\hline Question 3: Days missed & - & - & - & - & \\
\hline from housework & - & - & - & - & - \\
\hline Mean $(95 \%$ CI $)$ & $4.2(-0.2-8.6)$ & $5(0.8-9)$ & $0.8: 1$ & $4.7(1.6-7.7)$ & -8806 \\
\hline Range & $0-46$ & $0-65$ & - & $0-65$ & 0.806 \\
\hline Question 4: Reduction & - & - & - & - & - \\
\hline effectiveness in & - & - & - & - & - \\
\hline housework & - & - & - & - & - \\
\hline Mean $(95 \% \mathrm{CI})$ & $3.2(-0.5-6.4)$ & $2(0.5-3.4)$ & $1.6: 1$ & $2.3(1-3.8)$ & 0.412 \\
\hline Range & $0-30$ & $0-30$ & - & $0-30$ & - \\
\hline Question 5: Days missed & - & - & - & - & - \\
\hline from family, social or & - & - & - & - & - \\
\hline leisure activities & - & - & - & - & - \\
\hline Mean $(95 \%$ CI $)$ & $1.5(-0.6-3.6)$ & $2.1(-0.3-4.6)$ & $0.8: 1$ & $1.9(0.2-3.6)$ & 0.731 \\
\hline Range & $0-20$ & $0-50$ & - & $0-50$ & - \\
\hline Total MIDAS score & - & - & - & - & \\
\hline Mean $(95 \%$ CI) & $11(1.4-20.7)$ & $16(2.9-29.1)$ & $0.6: 1$ & $14.3(5.2-23.3)$ & $0 .-\overline{606}$ \\
\hline Range & $0-85$ & $0-246$ & - & $0-246$ & 0.000 \\
\hline
\end{tabular}

Table 6. MIDAS Score: Mean and range of days with headache and pain intensity in the past 3 months.

\begin{tabular}{cccccc}
\hline Questions & Males & Females & $\begin{array}{c}\text { Ratio } \\
\mathrm{m} / \mathbf{f}\end{array}$ & Total & P-value \\
\hline $\begin{array}{c}\text { Question A: Headache } \\
\text { days in last 3 months }\end{array}$ & - & - & - & - & - \\
Mean (95\% CI) & $5.3(1-9.5)$ & $6(2.5-9.4)$ & $0.8: 1$ & $5.7(3.1-8.4)$ & - \\
Range & $0-42$ & $0-60$ & - & $0-60$ & 0.873 \\
$\begin{array}{c}\text { Question B: Pain intensity } \\
\text { Mean (95\% CI) }\end{array}$ & $-1.1(2.3-5.8)$ & $4.2(3.1-5.4)$ & $1: 1$ & $4.2(3.3-5.1)$ & 0.943 \\
Range & $0-10$ & $0-10$ & - & $0-10$ & -
\end{tabular}

Table 7. Distribution of disability scores.

\begin{tabular}{ccccc}
\hline & $\mathrm{N}(\%)$ & Males & Females & P value \\
\hline I & $43(62.3)$ & $15(62.5)$ & $28(62.2)$ & \\
II & $7(10.1)$ & $3(12.5)$ & $4(8.9)$ & \\
III & $10(14.5)$ & $3(12.5)$ & $7(15.6)$ & \\
IV & $9(13)$ & $3(12.5)$ & $6(13.3)$ & 0.958 \\
\hline
\end{tabular}


the migraineurs had moderate to severe disability due to migraine.

The lifetime prevalence of migraine in this study (as well as in males and females) is similar to some studies from the continent and different from others [1] [3] [4] [5] [6] [7] [19] [20] [21] [22] [23]. In a community based study in Enugu we reported a migraine prevalence of $6.7 \%$ and $7.1 \%$ in the $20-29$ age group and 30 - 39 age groups [2]. Findings are slightly lower than the index study. The differences between the index study and some earlier reports may be attributed to population specific characteristics and different work and school environments.

Migraine with aura has been reported in few studies in the continent [2]. Migraine without aura in this study takes the higher proportion of migraine headache which is $88.4 \%$ and that of migraine with aura was $17.6 \%$ of migraine headache in general; this is true in most studies [2] [24] [25] [26].

About $40.6 \%$ were concerned about having headache which suggests at least to some extent of possible severe attacks. This is congruent with the fact that a similar proportion consulted their physicians during the period. Migraine is a chronic health problem that has an impact on both the individual sufferer and on society [9] [10] [11] [12] [14] [15]. In addition to attack-related disability, many migraineurs live in fear, knowing that at any time an attack could disrupt their ability to work, care for their families and/or carry out their social obligations. Furthermore, migraineurs experience problems in interpersonal relationships because of guilt about their incapability of fulfilling their family duties or they are afraid that a migraine attack will interfere with their family activities [27]. Thus, leading to frustration, anger, depression, and helplessness and thus to affect patient's well-being [27].

The proportion who sought medical attention was within the range of $16 \%$ $66 \%$ reported in other studies [5] [28]. People with migraine may not consult or continue orthodox treatment because of several reasons. Some may believe that their doctors do no empathize with them [29] while other factors may include lack of neurologists and specialist thus migraineurs may not actually benefit hospital visits. High cost of specialist consultations may be another possible factor.

Headaches and other pain disorders account for in major consumption of over-the-counter medications (OTCs). The difference between those who spent money of treatment (39.4\%) (most likely on medications) and those who actually visited a doctor (30.4\%) may allude to self-medication. In SSA where drugs are poorly regulated, substandard/ineffective drugs easily accessible and prescription ethics not fully complied with, it is possible that the cost of OTCs attributed to migraine may even be higher. The prevalence of possible medication overuse headache reported in Zambia was 7.1\% [21].

About $30.4 \%$ of migraineurs said that their overall academic performance was affected by migraine within the previous 3 months. In a study among university students by Timothy et al. [7], about $64.8 \%$ of the respondents reported that 
their academic performance was affected by migraine. Among secondary school students in Benin City, Nigeria, 76.8\% of secondary school students reported inability to participate in outdoor activities, household chores, and school absenteeism [6].

Another interesting finding in this study show a that $24.6 \%$ of migraineurs had a family history of similar headache. Genetic epidemiologic studies show that migraine clusters in families and with different degrees of heritability and may be co transmitted with other disorders [30] [31].

Based on the MIDAS scores students were more likely to have five or more days of reduced days of effectiveness at school and days missed from housework. This may suggest that at home, students were more likely to be exempted from domestic chores by their parents or guardians. On the other hand, these same students continue to attend classes (2.9\% absenteeism from school) despite the fact that may not function effectively during lessons (18.8\% reduction in effectiveness at school). Similar explanation may be given for questions 3 and 4 suggesting that many migraineurs continue on their school activities despite severe limitations. Migraine can be triggered by examination related factors [7] therefore likely to affect the overall performance of students even if these students do not report significant impact in-between exams. The burden and impact of migraine owing to lost work and school hours need to be properly addressed in the continent. This calls for adoption of proper school health programs to improve of ongoing low awareness and low quality of care. Promoting access to care at community-level, developing health infrastructure, training and research at facility-level can help reduce this multi-faceted problem [13]. These measures may be started in schools with the formation of health clubs and wellness groups. Lifestyle modification to address such non-communicable disorders including headache should be emphasized at such gatherings.

The mean number of days of disability in various domains based on the MIDAS questionnaire was similar in males and females. The ratio was tilted towards females except in question 3. The mean global score shows that migraineurs were disabled in 14.3 days in 3 months equivalent to 57.2 days in a year. Similarly, migraineurs had an equivalent of 22.8 days of headache in a year; half the number of days with headache supporting the fact that migraine related disability stretches beyond the actual pain. In the American Migraine Study II, 92\% of women and $89 \%$ of men with severe migraine had some headache-related disability [27]. Lofland and Frick [28] reported that 76.5\% of migraineurs missed some time from work with an annual average of 4.4 days. In the UK [14] a survey of hospital workers found that $24 \%$ of migraine sufferers had taken some time off work due to their migraines over the preceding 3 months. In the Migraine and its Effects on Life and Treatment (MELT) [32] survey which interviewed subjects with similar age group of the index study, participants had an average 2 days of absence and 4 days of reduced function at work or school.

In the present study, migraine sufferers spent 1.6 days at school with an attack 
in 3 months equivalent to approximately 6.4 days in a year while 14.8 days of reduction in effectiveness at school was reported. This is supported by the proportion of students who stated that migraine has affected their school performance. The most substantial element of total working time lost due to migraine in this study stems from days missed from housework findings are higher than some findings in the West [14] [16]. These findings are comparable to our findings.

Concerning headache frequency and pain intensity, the IBMS [8] demonstrated that persons with migraine had longer duration of headache attacks and were likely to experience severe pain intensity. In the US, $25 \%$ of women who have migraine experience four or more severe attacks a month; 35\% experience one to four severe attacks a month; $38 \%$ experience one, or less than one, severe attack a month [27] with similar frequency patterns were observed for men. In the MELT survey participants reported an average of 23 migraine or other severe headaches per year [32]. In the present study the mean number of days was 5.7 in the preceding 3 months or equivalent to 22.8 days in a year.

Generally, poor healthcare infrastructure, poverty and lack of human resources undermine negatively impact on access to care in migraine. This resultant wide treatment gap for primary headaches implies a higher disability rate in the continent even if the prevalence is still assumed to be low.

The main strength of this study was in documenting the disability of migraine among young Nigerians in the school environment. To the best of our knowledge, this is the first time such a study was undertaken in South East Nigeria. Low income, lack of access to adequate care and other factors such as intense heat, poor feeding habits and stressful academic activities may precipitate and sustain primary headaches thus aggravating the level of disability caused by migraine. Therefore, the true burden of migraine may be very high among young Nigerians.

\section{Limitations}

The strict use of ICDH III beta may underestimate mild forms of migraine and exclude some who may have the condition. Other limitations include the relatively smaller number of subjects with migraine studied, cultural and social issues may make subjects to deny or trivialize the severity of headaches especially where they are easily treated with locally available medications. Finally, our findings may be affected by recall bias in describing the characteristics of the headaches as well as their duration. All data were self reported and there were no supporting medical records or data accessed.

\section{Conclusions}

The prevalence of migraine is high among students in south East Nigeria. In the preceding three months, $30 \%-40.6 \%$ of migraineurs were concerned about headache attacks; consulted a doctor; used medications for headache and said 
that the headache affected their overall performance at school. Most students were affected due to reduced effectiveness at school and number of days missed from housework. Overall, $47.8 \%$ had at least one day affected by headache with an average of 14.3 days disabled by headache. The mean headache frequency was 5.7 days and headache intensity was 4.2 . In all, $27.5 \%$ of the migraineurs had moderate to severe disability due to migraine.

Recommendations: Teachers and school-based health providers should be trained to recognize common types of headache and their first aid treatment. School authorities should be made to understand that headache (especially migraine) is not just "simple malady" but can affect the academic performance of students. Possible parents should be encouraged to take their children to headache care specialists or neurologists if symptoms are severe or recurrent.

\section{Acknowledgements}

The authors are grateful to the Administrators, Teaching Staff and students of the educational institutions which served as sites for this study, we are also grateful to Miss Loveth Emmanuel, Secretary, Neurology and EEG services, Mount Carmel Hospital Enugu, for her help in the office.

\section{Conflicts of Interest}

The authors declare no conflicts of interest regarding the publication of this paper.

\section{References}

[1] Ezeala-Adikaibe, A.B., Ekenze, O.S., Onwuekwe, I.O. and Ulasi, I.I. (2012) Frequency and Pattern of Headache among Medical Students at Enugu, South East Nigeria. Nigerian Journal of Medicine, 21, 205-208.

[2] Ezeala-Adikaibe, B.A., Onyekonwu, C., Okudo, G., Onodugo, O., Ekenze, S., Orjioke, C., Chime, P., Ezeanosike, O., Mbadiwe, N., Chikani, M., Okwara, C., Ulasi, I. and Ijoma, U. (2014) Prevalence of Primary Headaches in an Urban Slum in Enugu South East Nigeria: A Door-to-Door Survey. Headache, 54, 1601-1610. https://doi.org/10.1111/head.12465

[3] Kolawole, W.W. and Asuwemhe, J.U. (2009) Migraine: Prevalence and Associated Disability among Nigerian Undergraduates. The Canadian Journal of Neurological Sciences, 36, 216-221. https://doi.org/10.1017/S0317167100006570

[4] Onwuekwe, I.O., Ezeala-Adikaibe, B.A. and Ekenze, O.S. (2012) Neurological Disease Burden in Two Semi-Urban Communities in South East Nigeria. Nigerian Journal of Medicine, 21, 317-319.

[5] Oshinaike, O., Ojo, O., Okubadejo, N., Ojelabi, O. and Dada, A. (2014) Primary Headache Disorders at a Tertiary Health Facility in Lagos, Nigeria: Prevalence and Consultation Patterns. BioMed Research International, 2014, Article ID: 782915,.

[6] Ofovwem, G.F. and Ofili, A.N. (2010) Prevalence and Impact of Headache and Migraine among Secondary School Students in Nigeria. Headache, 50, 1570-1575. https://doi.org/10.1111/j.1526-4610.2010.01776.x

[7] Timothy, S.Y., Mava, Y. and Bwala, A.Y. (2012) Impact of Acute Migraine Head- 
ache amongst University Students in Northeastern Nigeria. International Research Journal of Pharmacy, 3, 134-136.

[8] Blumenfeld, A., Varon, S., Wilcox, T.K., Buse, D., Kawata, A.K., Manack, A., Goadsby, P.J. and Lipton, R.B. (2010) Disability, HRQoL and Resource Use among Chronic and Episodic Migraineurs: Results from the International Burden of $\mathrm{Mi}$ graine Study (IBMS). Cephalalgia, 31, 301-315.

[9] Wang, S.J., Wang, P.J., Fuh, J.L., Peng, K.P. and Ng, K. (2013) Comparisons of Disability, Quality of Life, and Resource Use between Chronic and Episodic Migraineurs: A Clinic-Based Study in Taiwan. Cephalalgia, 33, 171-181. https://doi.org/10.1177/0333102412468668

[10] Buse, D.C., Manack, A.N., Serrano, D., Turkel, C. and Lipton, R.B. (2012) Headache Impact of Chronic and Episodic Migraine: Results from the American Migraine Prevalence and Prevention Study. Headache, 52, 3-17. https://doi.org/10.1111/j.1526-4610.2011.02046.x

[11] Bloudek, L.M., Stokes, M., Buse, D.C., Wilcox, T.K., Lipton, R.B., Goadsby, P.J., Varon, S.J., Blumenfeld, A.M.M., Katsarava, Z., Pascual, J., Lanteri-Minet, M., Cortelli, P. and Martelletti, P. (2012) Cost of Healthcare for Patients with Migraine in five European Countries: Results from the International Burden of Migraine Study (IBMS). Journal of Headache and Pain, 13, 460. https://doi.org/10.1007/s10194-012-0460-7

[12] Kim, S. and Park, S. (2014) The Role of Headache Chronicity among Predictors Contributing to Quality of Life in Patients with Migraine: A Hospital-Based Study. Journal of Headache and Pain, 15, 68. https://doi.org/10.1186/1129-2377-15-68

[13] Woldeamanuel, Y.W., Andreou, A.P. and Cowana, R.P. (2014) Prevalence of Migraine Headache and Its Weight on Neurological Burden in Africa: A 43-Year Systematic Review and Meta-Analysis of Community-Based Studies. Journal of the Neurosciences, 342, 1-15. https://doi.org/10.1016/j.jns.2014.04.019

[14] Clarke, C.E., Macmillan, I., Sondhi, S. and Wells, N.E. (1996) Economic and Social Impact of Migraine. QJM: An International Journal of Medicine, 89, 77-84. https://doi.org/10.1093/oxfordjournals.qjmed.a030141

[15] Diener, H., Steiner, T.J. and Tepper, S.J. (2006) Migraine-The Forgotten Epidemic: Development of the EHF/WHA Rome Declaration on Migraine. Journal of Headache and Pain, 7, 349. https://doi.org/10.1007/s10194-006-0349-4

[16] Bigal, M.E., Rapoport, A.M., Lipton, R.B., Tepper, S.J. and Sheftell, F.D. (2003) Assessment of Migraine Disability Using the Migraine Disability Assessment (MIDAS) Questionnaire: A Comparison of Chronic with Episodic Migraine. Headache, 43, 336-342. https://doi.org/10.1046/j.1526-4610.2003.03068.x

[17] Lipton, R.B., Liberman, J.N., Kolodner, K.B., Bigal, M.E., Dowson, A. and Stewart, W.F. (2003) Migraine Headache Disability and Health-Related Quality-of-Life: A Population-Based Case-Control Study from England. Cephalalgia, 23, 441-450. https://doi.org/10.1046/j.1468-2982.2003.00546.x

[18] Headache Classification Committee of the International Headache Society (2013) The International Classification of Headache Disorders. 3rd Edition. Cephalalgia, 33, 629-808.

[19] Lwanga, S.K. and Lemeshow, S. (1991) Sample Size Determination in Health Studies: A Practical Manual. World Health Organization, Geneva.

[20] Gelaye, B., Peterlin, B.L., Lemma, S., Tesfaye, M., Berhane, Y. and Williams, M.A. (2013) Migraine and Psychiatric Comorbidities among Sub-Saharan African Adults. Headache, 53, 310-321. https://doi.org/10.1111/j.1526-4610.2012.02259.x 
[21] Mengistu, G. and Alemayehu, S. (2013) Prevalence and Burden of Primary Headache Disorders among a Local Community in Addis Ababa, Ethiopia. Journal of Headache and Pain, 14, 30. https://doi.org/10.1186/1129-2377-14-30

[22] Mbewe, E., Zairemthiama, P., Yeh, H., Paul, R., Birbeck, G.L. and Steiner, T.J. (2015) The Epidemiology of Primary Headache Disorders in Zambia: A Population-Based Door-to-Door Survey. Journal of Headache and Pain, 16, 30. https://doi.org/10.1186/s10194-015-0515-7

[23] Haimanot, T.R., Seraw, B., Forsgren, L., Ekbom, K. and Ekstedt, J. (1995) Migraine, Chronic Tension-Type Headache, and Cluster Headache in an Ethiopian Rural Community. Cephalagia, 15, 482-488. https://doi.org/10.1046/j.1468-2982.1995.1506482.x

[24] Adoukonou, T., Tognon-Tchegnonsi, F., Philomène, K., Alabi, A., Houinato, D. and Preux, P. (2014) Prevalence of Migraine among University Students at Parakou, Benin: A Cross-Sectional Study. World Journal of Neuroscience, 4, 18-24.

https://doi.org/10.4236/wjns.2014.41003

[25] Alzoubi, K.H., Mhaidat, N., Al Azzam, S., Khader, Y., Salem, S., Issaifan, H. and Haddadin, R. (2009) Prevalence of Migraine and Tension-Type Headache among Adults in Jordan. Journal of Headache and Pain, 10, 265-270. https://doi.org/10.1007/s10194-009-0122-6

[26] Deleu, D., Khan, M.A. and Al Shehab, T.A. (2002) Prevalence and Clinical Characteristics of Headache in a Rural Community in Oman. Headache, 42, 963-973. https://doi.org/10.1046/j.1526-4610.2002.02225.x

[27] Bener, A. (2006) Frequency of Headache and Migraine in Qatar. Neuroepidemiolo$g y$, 27, 61-66. https://doi.org/10.1159/000094579

[28] Lipton, R.B., Stewart, W.F., Diamond, S., Diamond, M.L. and Reed, M. (2001) Prevalence and Burden of Migraine in the United States: Data from the American Migraine Study II. Headache, 41, 646-657. https://doi.org/10.1046/j.1526-4610.2001.041007646.x

[29] Lipton, R.B., Stewart, W.F. and Simon, D. (1998) Medical Consultation for Migraine: Results from the American Migraine Study. Headache, 38, 87-96. https://doi.org/10.1046/j.1526-4610.1998.3802087.x

[30] Dueland, A.N., Leira, R. and Cabelli, S.T. (2005) The Impact of Migraine on Psychological Well-Being of Young Women and Their Communication with Physicians about Migraine: A Multinational Study. Current Medical Research and Opinion, 21, 1297-1305. https://doi.org/10.1185/030079905X56394

[31] Russell, M.B., Iselius, L. and Olesen, J. (1996) Migraine without Aura and Migraine with Aura Are Inherited Disorders. Cephalalgia, 16, 305-309. https://doi.org/10.1046/j.1468-2982.1996.1605305.x

[32] Merikangas, K.R., Merikangas, J.R. and Angst, J. (1993) Headache Syndromes and Psychiatric Disorders: Associations and Familial Transmission. Journal of Psychiatric Research, 27, 197-210. https://doi.org/10.1016/0022-3956(93)90008-P 